\title{
The Reform and Discussion of Teaching Course System of University-enterprise Cooperation Training Mode for Electronic Information Professional
}

\author{
Zhong-xun WANG ${ }^{1}$, Kang-kang DU ${ }^{2}$ \\ 1) Institute of science and technology for Opto-Electronics information, Yantai University, Yantai Shandong, CHINA \\ 2) Institute of science and technology for Opto-Electronics information, Yantai University, Yantai Shandong, CHINA
}

\begin{abstract}
The reform of teaching course system of university-enterprise cooperation training mode is to allow enterprises to participate in the entire process of training students. It can formulate the scheme of teaching course system according to the actual situation of the development of the industry, and enhance students' theoretical level and practical ability by introducing the industry's most cutting-edge technology or the researching project in the enterprise itself. Practice has proved that the reform of teaching course system of university-enterprise cooperation training mode for electronic information professional can bring tripartite benefit among universities, enterprises and students.
\end{abstract}

Keywords -comprehensive talents; university-enterprise cooperation; teaching course system; electronic information

\section{电子信息类专业校企联合培养模式教学课 程体系改革初探}

王中训 $^{1}$ 杜康康 $^{2}$

1) 烟台大学光电信息科学技术学院, 烟台, 山东, 中国

2) 烟台大学光电信息科学技术学院, 烟台, 山东, 中国

摘 要 校企联合培养模式教学课程体系改革是让企业全程参与学生的培养过程, 根据行业发展的实际情况来制定教学课程体系 和方案, 通过引入行业最前沿的技术和企业本身的在研项目来增强学生的理论水平和实践动手能力。实践证明, 电子信息类专业校企 联合培养模式教学课程体系改革可以带来高校、企业、学生三方共赢的效果。

关键词 全面人才, 校企联合, 教学课程体系, 电子信息

\section{1. 引言}

近年来, 随着国家电子技术和信息技术的快速发展, 市场竞争日趋激烈, 市场对电子信息类专业全面人才的需 求呈逐年增加之势。高等学校电子信息类专业现有的教学 课程体系偏重于理论, 忽视了实践环节, 导致电子信息类 专业学生与市场需求脱节 $[1]$ 。本文从国内高校电子信息类 专业的教学现状出发, 针对电子信息类专业学科之间的交 叉融合, 以校企联合培养模式为着力点, 从培养体系、课 程平台以及教学模式等方面探讨了电子信息类专业课程体
系改革的措施。

2. 传统电子信息类专业课程体系设置现状及存在的 问题 [2]

培养符合社会需求的高质量人才是高等教育的宗旨, 也是本科教育的出发点。一直以来, 受人才培养定位不清 的影响, 多数院校在电子信息类专业课程体系构建上的思 路不清晰, 主要表现在课程体系的建设上存在定位不清, 培养出来的人才不能符合社会的需要。电子信息类专业是 
内容丰富、要求较高、综合性强的学科专业。它涉及电子 信息技术、无线电通信技术、传感与控制技术和计算机应 用技术等多门学科。从我们学校及其他院校目前的教学课 程体系来看，电子信息类等专业传统课程体系存在如下主 要问题:

(1) 传统电子信息类专业课程体系知识覆盖不全 从行业对人才的需求来看, 适合行业发展的人才需具 备的知识涉及电子技术、无线电技术、传感与测试技术、 控制技术和计算机应用技术等多学科技术。而这些技术分 别属于电子信息科学与技术类、电子信息工程类和仪器仪 表类专业。但是, 由于各方面原因, 很多院校对这些专业 的课程设置一般都会偏向某一领域, 导致课程设置不全或 知识点覆盖不够。例如电子信息类专业的课程设置就往往 会偏重电子技术和信息处理技术以及传感与测试技术, 而 计算机应用技术方面的课程就相对较弱, 不能满足行业对 人才全面发展的需求。

（2）传统电子信息类专业课程体系结构不够合理

受各种因素的影响, 在很多高校的电子信息类课程体 系中, 理论课程所占比重过大, 而实践环节比重过小。在 这种体系结构下, 培养出的学生多是 “理论型”。当今社会 进入信息科技时代, 需要大批 “全能型” 人才。高校应当 转变培养思路, 人才培养模式应从 “理论型” 向 “全能型” 转变, 而加强实践应用环节的教学, 利用校企联合培养模 式引进企业的前沿技术来促进学生的理论和实践的结合, 是培养 “全能型” 人才的有效措施。

(3) 传统电子信息类专业课程体系教学内容不够完善

高等教育的任务是培养具有一定的实践动手能力的符 合社会发展的全面人才, 可见高等教育在国家人才培养体 系中有着非常重要的地位。然而, 从目前的大学生的实际就 业情况来看, 经常出现如下情况: 学生的理论知识很丰富 但动手能力较弱, 或者是学生掌握的理论知识较落后, 不 能适应最前沿的技术需要。这些问题反映了传统电子信息 类专业课程体系存在重传授理论知识、轻培养实践能力; 重传统知识的传承、轻前沿技术的学习等问题。虽然部分 高校通过增加实验课来加强实践环节, 以求增强学生的实 践动手能力。但实验课的操作内容与最新的行业前沿技术 脱节严重, 实验操作内容相对单一, 学生存在一定程度的 抄袭现象, 造成高校培养的人才无创新发展意识、实践能 力较弱等现象。

\section{3. 电子信息类专业课程体系改革的基本原则 [1]}

(1) 以培养适合行业需求的高素质全面人才为目标来 设置课程体系, 把行业中最前沿的技术, 特别是电子信息 科学技术方面的最新研究成果和知识引入课程体系中, 突
出教学内容的时代性和适应性。

（2）站在行业整体的高度上构建新型课程体系, 构建 涵盖学科基础理论、公共基础理论和实践动手能力平台的 多元化课程体系, 引导学生由 “理论型” 向 “全能型 “转 变。

(3) 注重加强学生实践动手能力的培养, 通过在新的 课程体系中引入校企联合培养模式中企业的技术力量来增 强学生的实践动手能力, 使学生能将知识和能力进行有机 结合, 使学生能早日满足行业的需求。

(4) 更新教学内容重构课程体系, 以电子信息类专业 课程体系改革为契机, 注重加强教材理论性和适应性建设, 注重加强理论前沿性建设, 构建既有理论性又符合行业发 展的新型教材体系。

\section{4. 电子信息类课程体系改革 [4]}

电子信息类专业校企联合培养模式课程体系改革是让 企业参与高校课程体系的制定与实施, 利用企业的专业资 源对学生进行培训, 能锻炼学生的实践动手能力, 实现电 子信息类专业人才的培养与市场需求无缝链接。而校企联 合培养模式能加强高校与企业的交流, 搭建高校理论教学 与企业前沿技术对接的基础实验平台, 将企业前沿技术引 入到高校理论教学当中, 创新高校理论教学路径, 增加实 践教学环节, 通过参与校企联合培养企业的在研项目, 使 学生能在学好理论的同时掌握行业最前沿的技术, 能起到 增强学生就业竞争力的作用; 同时, 校企联合培养模式教 学课程体系也鼓励企业参与教学, 培养符合企业自身需求 的人才, 从而增强企业人力资源优势。符合行业发展和企 业需求的复合型人才需要掌握电子信息类专业基础知识和 行业前沿的技术。对于校企联合培养模式下的电子信息专 业课程体系采用 “学科基础理论平台+公共基础理论平台 + 实践平台” 的结构。

（1）夯实基础, 构建电子信息类专业学科基础理论平台

目前高校电子信息类专业基础理论课程主要包括电路 分析基础、信号与系统、电路信号与系统实验、模拟电子 技术基础、数字电路与逻辑设计、数字信号处理、电磁场 与电磁波、射频电路等。应整合目前的电子信息类专业基 础课程, 构建基础理论平台, 使学生能扎实学习这些专业 基础知识, 为以后工作中的创新打下坚实的基础, 有利于 增强行业适应力。在搭建电子信息类专业基础理论平台的 过程中, 要尽量减少各课程间的重复, 同时又要把握各课 程间的融合。通过校企联合培养模式的实施, 进一步对电 子信息类专业学科基础理论课程进行整合优化, 加大企业 在研项目参与教学比重, 加强实验实践教学比重, 培养学 生的动手能力。 
（2）积极拓展, 构建电子信息类专业公共基础课程理论平 台

公共基础课程模块包括电子技术、计算技术基础课程、 无线电通信类课程以及测控技术课程。其中电子技术部分 课程主要有: 电路分析基础、模拟电子技术、数字电子技术; 计算技术部分课程主要有: C语言程序设计、微机原理及接 口技术、单片机原理及应用。无线电通信部分课程主要有: 信号与系统、高频电子线路、通信原理等课程。测控技术 课程模块主要包括传感器及检测技术、自动控制原理、计 算机控制系统等课程。这些课程均是电子信息类专业都必 须开设的公共基础课程。通过引入校企合作企业的技术力 量加强这些课程的教学, 为学生以后的就业奠定了坚实的 理论基础。

（3）全面发展，构建集中性实践教学平台

电子信息类专业各课程的实验部分都是围绕该课程内 容而开设的, 目的是为了巩固和加深对课程知识的理解和 掌握。为进一步提高学生对电子信息类专业各课程知识的 理解和运用, 有必要开展集中性实践教学环节。但是, 传统 的实践教学环节的内容过于老套, 严重滞后于行业实际情 况, 以至于培养的学生在实际工作中不能适应行业发展。 而新型的实践教学平台将企业的最前沿技术加入到学生的 日常课堂中, 让学生在校期间就参与到企业的在研项目中, 可以让学生的动手实践能力增强的同时，又能掌握一定的 最新前沿技术，同时，还能让企业招揽到既有丰富的理论 知识又有一定实践动手能力的优秀人才, 可以实现三赢。

（4）拓展视野，构建学生课外电子科技活动平台

由于高校学生的水平参差不齐, 有些同学在掌握好基 础知识的同时, 还想学习一些课外知识, 课外电子科技活 动平台就为这样的同学提供这样一个平台, 主要是组织学 生参加一些全国、省级的电子科技大赛、物联网大赛等电 子科技活动来拓展同学们的视野, 同时, 还可以与校企合 作企业联合举办电子科技竞赛，通过校企合作企业的专家 来拟竞赛题目, 现场讲授所需的理论知识, 然后同学们分 组进行竞赛，最后通过实物展示、答辩等环节评选出优秀 作品, 通过这样的电子科技竞赛可以增加同学们的理论知 识, 又可以增强同学们的实践动手能力, 让那些 “吃不饱” 的同学可以吃得饱。目前, 学院主要有EDA、FPGA实验室, 每年组织学生组队参加全国和山东省电子科技大赛，均取 得不俗成绩，同时，学院还联合烟台市三航电子科技有限 公司举办 “三航杯” 电子设计大赛, 迄今已举办四届, 在 同学中反响很大，极大地提高了学生的实践动手能力。

\section{5. 实施效果}

5.1 提高学生综合素质, 显著推动学生就业工作

通过对现有教学课程体系的改革进而构建新型电子信 息类专业课程体系, 学生不仅能够学习到行业最前沿的理 论知识, 而且将学生实践动手能力的培养融于教学的全过 程, 在注重知识传授的同时更加注重实践动手能力的培养, 融知识传授、能力培养与创新教育为一体, 造就适应行业 发展的全面人才。近 3 年以来, 我院电子信息类专业学生积 极参加各类科技竞赛活动和科技基金项目立项, 在全国电 子设计大赛、山东省电子设计大赛、 “挑战杯” 全国大学生 课外学术科技作品竞赛等科技竞赛活动中, 先后获得省级 及以上奖励 60 余项，获得发明专利 7 项，共获得校科技基金 立项 80 余项。通过校企联合培养模式的实施, 实现学生知 识和能力的有机结合, 为学生开辟了一条崭新的就业道路。 2015届毕业生首次就业率达 $80 \%$ 左右, 相当一部分学生进 入歌尔声学、富士康集团、东方电子等知名大型企业, 显 著推动了我院就业工作。

\section{6. 结束语 $[5]$}

校企联合培养模式课程教学体系改革是让企业全程参 与学生的培养过程, 根据行业发展的实际情况来制定课程 教学体系和方案, 通过引入行业最前沿的技术和企业本身 的在研项目来增强学生的理论水平和实践动手能力, 对高 校、企业和学生三方而言均有明显的优势：不仅可以改变 传统教学课程体系知识陈旧落后, 重理论轻实践的格局, 也可以使学生增强自己的实践动手能力, 使自己变成 “全 能型” 人才, 同时也可以使企业招聘到一上岗就能立刻产 生效益的优秀人才, 减少二次培训的时间和成本，可以大 幅度减少企业的人力资源成本。可以说, 校企联合培养模 式课程教学体系改革可以实现企业、高校和学生三方共赢 的局面。

\section{参考文献(References)}

[1] ZHENG Yi-xian. The practice and research of the personnel training mode of school and enterprise cooperation, Mechanical Vocational Education, 2009 (3)

[2] WANG Zhong-xun, ZHAO Jian-wei. Practice teaching system construction and research of electronic information science and Technology Specialty. International Conference on Psychology, Management and Social Science, 2013. 01

[3] WANG Qiu-hua, ZHANG Jian-wu etc. Discussion on the reform of the theory and practice teaching system of electronic 
information specialty in our school. Innovation of science and Technology Education, 2006 (17): 193

[4] ZHAO Han-qiang, ZENG Xing-wen etc. Exploration and Practice on the reform of the curriculum system of electronic information. The education of Industry and Information, 2013
(5) :25-27

[5] ZHANG Ying. Deepened the reform of teaching methods and constructed the training mode about innovative electronic information talents. Journal of Wuhan University (Science Edition), 2012 (10): 53-54 